\title{
FENOMENOLOGÍA DE LA MISERICORDIA Y EL EVANGELIO
}

\author{
Paul Gilbert \\ Universidad Gregoriana - Roma
}

\section{RESUMEN / ABSTRACT}

Misericordia significa "un corazón que es sensible a la miseria de los otros". Esta definición pone de manifiesto la síntesis de actividad y pasividad ambivalente que caracteriza la relación entre el misericordioso y el mísero, al tiempo que, desde un punto de vista fenomenológico trae consigo interesantes consideraciones sobre del perdón o de la simpatía. No obstante, querer superar los limites de estas dos realidades, hasta el punto de ponerse frente a la empatía, significa abandonar la perspectiva filosófica y adentrarse en la entraña del Evangelio, esto es, en el misterio de la Encarnación del Hijo de Dios.

Compassion means to have a heart that is sensible to others miseries. This definition explains the mix of activity and passivity ambivalence that characterizes the relationship between the merciful and the miserable. It also provides interesting considerations about the forgiveness and the sympathy. Nevertheless, to surpass the borders between these realities in order to get a fully empathy, means to give up the philosophical perspective and to get into the core of Gospel: the Mystery of the Incarnation of the Son of God.

\section{INTRODUCCIÓN}

La cultura actual de los medios de comunicación no es propicia a la debilidad, no la considera una virtud. En su encíclica Dives in misericordia, Juan Pablo II mostraba cómo, de hecho, "la 
mentalidad contemporánea, quizás en mayor medida que la del hombre del pasado, parece oponerse al Dios de la misericordia y tiende además a orillar de la vida y arrancar del corazón humano la idea misma de la misericordia. La palabra y el concepto de "misericordia" parecen producir una cierta desazón en el hombre, quien, gracias a los adelantos tan enormes de la ciencia y de la técnica, como nunca fueron conocidos antes en la historia, se ha hecho dueño y ha dominado la tierra mucho más que en el pasado" ${ }^{1}$.

El ideal propuesto por los medios de comunicación al hombre contemporáneo sería, de esta forma, el de vencer toda clase de desafios técnicos, el hombre ideal ya que es más fuerte en cada circunstancia, sale siempre victorioso. "El despertar de la fuerza", así reza el título de una película reciente ${ }^{2}$, el cual, según escuchamos en una publicidad omnipresente, ha de ser visto para no quedarse al margen de la cultura. La vida es una lucha. Quien vence, vive. Los que son débiles están ya casi muertos, o en cualquier caso son inexistentes.

El neo-liberalismo promueve así mismo comportamientos que son útiles para su ideología, para la innovación técnica, para la creación de instrumentos de control sobre la realidad; es decir, promueve el dinamismo de quien abandona las tradiciones para inventar caminos nuevos para un tipo nuevo de vida que se pretende "libre». El hombre imaginado por la cultura moderna está dotado por sí mismo de las fuerzas y las capacidades que le hacen no depender de nadie. No teme a nadie ni a cosa alguna.

Se dice, por el contrario, que el misericordioso no representa una actitud positiva, sino negativa. Su virtud no sería activa, sino reactiva. Nietzsche sostenía que la misericordia es debilidad, más aún, el "mayor de los peligros que acechan al hombre" ${ }^{3}$. El hombre tiene que ser fuerte y activo. El término "misericordia" significa "corazón mísero", es decir, que se abre a la miseria de los otros,

Juan Pablo II, Dives in misericordia, n. 2 (noviembre 1980).

Star Wars 7, de Jeffrey Jacob Abrams, 2015.

F. Nietzsche, La Gaia Ciencia, § 125, publicado en el 1882. 
que vive sin ignorar sus dificultades y que asume dicha disposición ética o disponibilidad espiritual. El misericordioso es empático. Dios sería el misericordioso por excelencia, no sólo porque espera al hijo pródigo y organiza una fiesta cuando regresa a casa, sino porque Jesús participa del destino humano, desde su nacimiento hasta su muerte.

"Señor, eres perdón y bondad, rico en amor para quien te invoca". Juan Pablo II nos recordaba que "Dios rico en misericordia" es Aquel que Jesucristo ha revelado como Padre: cabalmente su Hijo, en si mismo, nos lo ha manifestado y nos lo ha hecho conocern. El misericordioso según el Evangelio no sigue los caminos humanos que conducen a la victoria; antes bien, se arrodilla ante al misero y participa de su desgracia; para, al final, levantarlo de su mal. "Aun siendo de condición divina, no consideró un tesoro codiciable su ser igual a Dios; sino que se despojó de si mismo, asumiendo la condición de siervo y haciéndose igual a los hombres; apareció en forma humana, se humilló a sí mismo haciéndose obediente hasta la muerte y una muerte de Cruz. Por eso Dios lo ha exaltado"'.

Mi reflexión se desarrollará a partir de ahora en dos momentos. El primero pondrá en evidencia una dialéctica entre el misericordioso y el mísero. El segundo mostrará cómo esta dialéctica lleva a consideraciones radicales, metafísicas. El método que adoptaré será fenomenológico. Veremos, de hecho, todo lo que la fenomenología es capaz de clarificar nuestra comprensión de la historia de Jesús. En un artículo del 19967, Jean-Luc Marion proponía que la fenomenología de inspiración husserliana puede ayudar hoy a la reflexión teológica, del mismo modo que el platonismo lo había hecho en la época de los Padres y el aristotelismo con la Escolástica. El ensayo que propongo hoy mostrará hasta qué punto es posible dicha ayuda de la fenomenología contemporánea a la teología y al acto de fe.

Salmo 86,7.

Juan Pablo II, Dives in misericordia, n. 1.

Fil 2,6-9.

J.-L. MARIOn, "Phénoménologie de la donation et philosophie première» en ID., De Surcroît. Études sur les phénomènes saturés, Presses Universitaires de France (Perspectives critiques), Paris, 2001, 34. 


\section{EL MISERICORDIOSO Y EL MÍSERO: UNA DIALÉCTICA EXISTENCIAL}

\subsection{Léxico}

El término "misericordia" significa literalmente "un corazón que es sensible a la miseria de los otros". Hay en esta definición dos términos que debemos precisar, "corazón" y "miseria". El término "corazón" ha recibido siempre el significado de "fuente de afecciones". Si bien, indica la originalidad más profunda de la persona, la fuente más intima de su vitalidad. Cuando el corazón físico no funciona adecuadamente, el viviente entero enferma; todos sus órganos acabarán pereciendo por falta de oxígeno. El corazón es por ello más esencial que la inteligencia, la cual necesita de él: la inteligencia se pierde cuando el cerebro no es correctamente irrigado por el flujo de sangre impulsado hasta él desde el corazón. Parece además que el corazón es sensible, ya que regula su poder según las necesidades de las diferentes partes del cuerpo. Puesto que es sensible, se dice que es la sede de la afectividad.

Por tanto, el corazón, en realidad, no es solamente activo; es además pasivo; no sólo irriga el cerebro, sino que depende también de él, ya que éste le manda las informaciones necesarias sobre todas las partes del cuerpo con el fin de que pueda ser regulada su potencia muscular. El término "corazón" significa entonces la unidad corporal de actividad y pasividad que constituye nuestra fuente de vida. El término "miseria" señala, por su parte, al "que no ha tenido buen sino" o "ha sufrido alguna desgracia". El término "corazón" evoca por tanto la fuente de la vida, que es también afectividad, capacidad para reaccionar ante las informaciones recibidas; el término "miseria" significa por el contrario un destino maléfico que sufrimos sin posibilidad de reacción, a pesar de nuestra voluntad y de nuestros deseos.

La explicación de los términos ya lo indica: el misericordioso es capaz de reaccionar, esto es de actuar; el mísero, no. El primero goza de unas fuerzas interiores, de las que el segundo está desprovisto. El misericordioso posee un poder que le falta al mísero. Por esta razón, el misericordioso puede experimentar tentaciones que el mísero no sufrirá. En la relación del misericordioso y del mísero, la 
iniciativa arranca de la parte que tiene las posibilidades, el mísero está, sin embargo, sometido a lo inexorable. El misericordioso tiene la ventaja de poder actuar. Afirmar su superioridad es por ello una obviedad, una evidencia; ninguna razón podrá entonces moderar su buena voluntad. Pertenece a la propia situación: él puede, y por lo tanto debe, entregarse a realizar una obra buena. Quien posee el poder, si no lo ejercita, ¿lo tendrá verdaderamente? Un poder que no actúa, en realidad, es impotente.

La tentación, bajo capa de bien, se presenta ahora al misericordioso. Poderoso, el misericordioso, se piensa capaz de juzgar lo que será de utilidad para el mísero. Sino renuncia al propio poder, el poderoso no participará del sufrimiento del impotente y no será verdaderamente misericordioso. Sin embargo, ¿cómo podrá elevar al mísero de su sufrimiento si debe renunciar a la fuerza del propio poder?

Debemos poner de relieve, no obstante, que el misericordioso no puede ejercitar su poder si éste no es requerido. Desde este punto de vista, su situación de poderoso depende del mísero. No puede ejercitar su poder por sí mismo, sin el consentimiento de la persona a la que desea ayudar. Una tentación común a todas las buenas personas es la de pensar, apenas visto el misero, que son responsables de una misión que ha de prestar un poder del cual se juzgan capaces. El misericordioso piensa inmediatamente que él es el fuerte que debe salvar al débil. Sin embargo, para realizarlo de hecho, ha de someterse a las formas de miseria del misero, y ante todo a su libre llamada.

¿No será acaso obvio que quien no tiene nada dependa de quien tiene todo? ¿Cómo podremos, por tanto, decir con sensatez que, desde el punto de vista de la práctica concreta, el misericordioso depende también del mísero? Si el mísero no pidiera nada, a pesar de su buena voluntad, ¿qué podrá hacer el misericordioso? ¿Acaso el mísero no tendrá nunca nada que dar y el misericordioso siempre todo? De cualquier modo, el misericordioso no podrá mostrar su poder y ejercitarlo si el mísero no lo llama y si no acepta su ayuda.

Existe, además, otro problema, que manifiesta también la dependencia del misericordioso. ¿Cómo ayudar al mísero? El 
misericordioso no podrá dar aquello que no tiene, sino sólo lo que tiene a su alcance. La disponibilidad del misericordioso la determinan sus posibilidades concretas, o lo que es lo mismo, sus bienes; si,en cambio, quiere realmente ayudar, deberá quizá buscar otras posibilidades concretas, que no tiene.

Tales bienes pertenecen a diferentes géneros. Algunos son económicos, otros culturales. Habitualmente se pone el acento sobre los bienes económicos. Considero, sin embargo, que la utilidad de los bienes económicos depende de las necesidades y de los deseos de una determinada cultura. Desde este punto de vista, es importante distinguir entre las necesidades primarias o las secundarias. Sin embargo, ¿cuáles son los bienes de primera necesidad y cuáles no? Todos tenemos experiencia de darle comida a un mísero que pedía dinero. Todos tenemos experiencia de juzgar cuáles son los bienes "objetivos" y primarios requeridos por el mísero, esto es, experiencia de juzgar la escala de valores y de dignidad que la persona mísera parece asumir.

Esto que digo ahora al nivel del ciudadano común, sirve igualmente en las relaciones internacionales, tal es, de hecho, la experiencia de Europa desde hace más de medio siglo, desde la llamada descolonización. Los bienes llamados primarios, en realidad, ¿son solamente los económicos? ¿No serán más bien diferentes de una cultura a otra. Yo sostendría, sin problema alguno, que los bienes culturales son los verdaderos bienes primarios, y no solamente los bienes económicos ${ }^{8}$.

\subsection{Perdón y límites}

Hemos desplegado así la estructura fundamental y problemática de la misericordia humana. Para entrar en cuestiones específicas, consideremos el caso del perdón. Según el lenguaje común, el término "misericordia" no significa sólo un corazón que se dirige hacia el pobre, sino que inmediatamente señala además la idea de

8 Ver por ejemplo E.F. Schumacher, Small is beautiful. A studies of economics as if people mattered, London, 1976. 
perdonar. Sabemos cómo funciona nuestro corazón: ¿quién me dirá que no le ha asaltado nunca la idea de que el mísero es mísero por su culpa, que es el responsable de su miseria, aunque no quiera reconocerlo? ¡Qué dificil es perdonar a un culpable que no reconoce el propio pecado, que no quiere humillarse!

Los acontecimientos vividos recientemente en Europa (hablo de la migración de pueblos enteros) han empujado a muchos de nuestros conciudadanos, también en la Iglesia, a las zonas oscuras $\mathrm{y}$ turbadas del odio a los míseros que vienen hasta nosotros sin haber sido invitados.

El otro, sobre todo si viene de una cultura distinta a la mía, no es solamente otro; muchas cosas son "otras"; mi hermano es también otro respecto a mí. Sin embargo, el otro de otra cultura es, antes que nada, inquietante $\mathrm{y}$, por ello, peligroso; es susceptible a priori de ser acusado de cualquier tipo de crimen, de robar el trabajo, de robar ante todo los bienes. Su ser amenaza mi ser y me defenderé atacando. ¿Cómo será entonces posible la paz si no hay una relación justa entre las dos partes, entre el misericordioso y el mísero?

Nuestro estar en paz depende de la interiorización de una cultura que ofrece a todos una casa en la que poder vivir juntos y tranquilos, para poder entendernos con los demás. Cuando las culturas chocan, sin deseo alguno de ser fecundadas las unas por las otras, sobre todo cuando una cultura invade el espacio de la otra por razones económicas sin que ninguna de ellas desee compartir sus valores culturales, ni sea capaz de modificar sus propios códigos de convivencia, por ejemplo lingüísticos, esto es, cuando una casa espiritual o territorial es invadida por otras culturas y todas se mantienen en paralelo sin interacción, entonces la paz es complicada, imposible. Las luchas territoriales se inician de este modo, apoyadas sobre principios de identidades cerradas en sí mismas y que se excluyen a priori. Sabemos lo dificil que es afrontar hoy con inteligencia esta situación.

La inteligencia económica, entonces, no es suficiente. Ésta, de hecho, constituye un fenómeno de la espiritualidad humana, puesto que permite a una cultura expresarse de un modo particular, 
construir una casa para todos los que viven juntos, en la cercanía, para crear muchos proyectos. Al menos, así lo pensaron los filósofos modernos. Hoy, en Occidente, por el contrario, también en economía, las pasiones y las emociones son más enérgicas que la inteligencia. El que ve la televisión habitualmente o lee los periódicos, se convencerá fácilmente de que la violencia, nacida de pasiones más calculadoras y egoístas que de razón inteligente, se propone como norma de la cultura popular y de nuestras propias acciones.

Observamos, sin embargo, que no falta el respeto por la razón inteligente que persigue lo universal, ni la admiración por sus mediaciones a favor de la paz; la diplomacia, que expresa, por ejemplo, el rechazo de imponer la paz con la sola fuerza, es obra de la inteligencia. Violencia y diplomacia parecen de esta manera coexistir en una vida incoherente. Mientras que la cultura popular de la violencia se alimenta del miedo; los esfuerzos bienintencionados de la diplomacia expresan apuestas valientes de la inteligencia. Sin embrago, se confia poco en la diplomacia, cuyos resultados son siempre muy frágiles, objeto de continuas traiciones. Con todo, si la razón no se nutre de la inteligencia de afectos más profundos que el miedo al otro, se pierde en las luchas sofistas.

Volvamos de nuevo al perdón. El término "perdón" significa originariamente "don perfecto" o "don hecho a la perfección". De ahí que el perdón exprese el significado más profundo de cuanto lleva a cabo el misericordioso. En cambio, el sentido que habitualmente recibe hoy no parece referir una realidad buena. La idea de perdón implica, de hecho, la idea de culpa. Pero no todas las culpas son catastróficas. Hay cosas que se perdonan más fácilmente que otras. Se puede dar el perdón casi distraídamente. La experiencia es común; no hemos de insistir continuamente en todas las heridas sufridas. De hecho, muchas culpas han de ser juzgadas como insignificantes para sobrevivir. No es extraño que una persona a la que se pide perdón no vea por qué perdonar, ya que ni siquiera se había dado cuenta de que había sido herida.

9 Ver P. Gilbert, "Le pardon dans la culture contemporaine», en Studia Moralia 38 (2000) 405-435. 
Este ejemplo de perdón inútil es sin embargo indicativo: quien pide perdón, lo hace porque se inquieta ante su propio modo de actuar, quizá porque ha reconocido su inadecuación respecto al propio ideal de vida social. Aunque el perdón sea objetivamente de poca importancia, hará vivible la vida social de la persona que lo pide. Perdonar sólo porque el perdón es requerido, aunque ni se vea por qué, implica por ello devolver la vida a quien lo pide por un acto que él juzga equivocado. No podemos decir que el perdón devolverá sólo algo de la vida, ya que la vida no se divide en aspectos aislados entre sí. La vida es una en su conjunto, no se segmenta en compartimentos estancos. Perdonar, también perdonar una culpa de poco peso o perdonar sin esfuerzo, da la vida. El que perdona actúa con un poder creador, aunque la culpa perdonada fuera objetivamente insignificante.

\subsection{Perdón y vida}

El misericordioso que perdona se encuentra, por tanto, en una situación ambigua. Ser misericordioso (también en lo poco) significa ser capaz de dar la vida. El misericordioso posee en sí una potencia enorme, que va más allá de todo lo imaginable. Dejemos claro, no obstante, que no es omnipotente. El reconocimiento de la culpa y su confesión por parte del culpable son condiciones para ejercitar esa capacidad de perdón que está en él. Asistimos ahora de nuevo a la inversión de la situación. Hemos visto que uno puede juzgarse erróneamente culpable en razón de sus escrúpulos y, pero, estar equivocando. El misericordioso puede, también él, equivocarse, ver una culpa leve donde, por el contrario, el culpable la juzgaba de consideración. Pero no importan estas consideraciones para el culpable. En cualquier caso, el misericordioso actuará. Su proyecto será el de dar vida, aunque sea imposible conocer bien a la persona que ha de perdonar. Debemos por ello pensar que la suposición de la culpa, más que su propia realidad, sea la condición del perdón efectivo. La capacidad de perdonar es en nosotros un poder creador del que no podemos saber su fecundidad.

Todo perdón inicia una historia imprevisible. Entre el misericordioso y el culpable hay una red de condiciones reciprocas que nunca se encuentran equilibradamente. La situación es muy 
compleja, hasta el punto de que podría parecer fuente de injusticia. El misericordioso que inicia su camino sin ser requerido, parece anticipar el reconocimiento de la propia culpa del culpable. Es más, cree ver mejor la culpabilidad del culpable que él mismo. El misericordioso partiría por tanto de una consideración negativa, de una sospecha sobre la cualidad ética del presunto culpable, que hace éste un culpable real a sus ojos. Lo juzga antes que él mismo reconozca su mal. Así, el misericordioso condena antes al otro, después lo ayudará. Tendrá quizá razón, y el reconocimiento por parte del culpable de su estado espiritual de culpabilidad será una victoria de su conciencia ética. La actitud acusadora originaria del misericordioso pervierte sin embargo la bondad de la ayuda que entregará después, porque habrá dado la muerte antes de dar la vida.

Sin embargo, es importante poner de relieve que el auténtico misericordioso no se alegrará de que su mirada de condena haya visto el estado del culpable antes de que él mismo lo hubiera reconocido, más bien, se alegrará de la capacidad que el culpable tiene de tomar las riendas de la situación, de convertirse, de cambiar la orientación de su vida. En este sentido, el misericordioso es profeta y anticipa el perdón; su mirada parece de condena; pero realmente es de espera y de amor. Ve las riquezas humanas escondidas en los hombres y apuesta porque le están a priori disponibles para un cambio hacia la santidad. Dice al culpable: "tú vales mucho más que tus acciones" ${ }^{10}$ y que tus representaciones de ti mismo. Tu valor es distinto de lo que estás pensando de ti y de lo que yo había pensado de ti. Invita de este modo al malvado a cambiar la mirada sobre sí mismo, a esperar porque el bien está siempre a su alcance; le dice que su mirada sobre sí mismo le revelaba su mal, que ese mal no es su identidad. El misericordioso es, en este sentido, un liberador, un salvador. Vive de esperanza y sus juicios negativos sobre el misero estaban fundados sobre esta virtud, es decir, sobre la disponibilidad a creer en las posibilidades de progreso del culpable.

10 P. Ricceur, La mémoire, l'histoire, l'oubli, Seuil (Points. Essais), Paris, 2000, 642. 


\section{LA MISERICORDIA Y LA MISERIA: UNA ESENCIA FENOMENOLÓGICA}

El ejercicio de la misericordia hacia un culpable corre el riesgo, a primera vista, de ser injusto cuando se lleva a cabo sin un análisis cuidadoso de la situación; podría no respetar la realidad de la persona a la que se dirige, y ni siquiera la propia realidad de la persona misericordiosa. Hacemos notar que el término "realidad" recibe aquí un enfoque esencialmente metafísico. La realidad metafísica no es la realidad factual. Misericordioso y mísero son obviamente realidades "físicas", factuales o numéricamente iguales, pero diversas desde un punto de vista metafísico. No es el conocimiento actual de una situación el que lleva al reconocimiento de toda la verdad.

Un primer análisis muestra cómo el misericordioso tiene la posibilidad de actuar, es poderoso; el mísero, por el contrario, es impotente. La relación del misericordioso y del mísero no pertenece al orden de las realidades factuales, sino de las posibilidades. Propongo por ello una afirmación que obviamente hoy será percibida como escandalosa, y lo es. Si el término "realidad" connota en metafisica una capacidad o una potencia efectiva de realización, el misericordioso y el mísero tienen un valor distinto.

\subsection{Léxico}

El término "metafísica", con su matiz de posibilidad y, por tanto, de valor o de finalidad, trae consigo un aspecto ético. En este sentido, es también "metamoral". La especificidad de la moral no es, de hecho, la de calificar el valor, sino la de establecer en un código las condiciones de cumplimiento de los deberes prescritos. El mundo de la moral es el de la necesidad. La moral considera, de hecho, la naturaleza numéricamente idéntica de todos los individuos que convergen en una sociedad o en una cultura. La ética, sin embargo, medita sobre el fundamento de los códices morales, esto es, sobre una jerarquía ideal de valores de hacia los cuales el acto de ser de las personas (el "actus essendi" de la tradición) es efectivamente capaz puesto en acto; considera por ello los modos diferenciados de las personas que actúan en el sistema social, aunque las diferencias 
de estos modos no sean cuantificables. Para la moral, las personas están todas sometidas a normas que se aplican igualmente para todos. La metafísica y la ética consideran, por el contrario, el orden de los valores que valen por sí mismos y no en función de su aplicación, el orden de los valores, en este sentido, deseables de diferentes modos. La moral considera el deber-ser, la ética y la metafisica, por su parte, el ser poderoso mismo en acto.

En sí mismas, las realidades humanas, hombres y mujeres, son ricas en posibilidades, habitualmente ocultas y nunca puestas en acto totalmente; su actividad depende de una suma indeterminada de condiciones externas, de su mundo físico, psicológico, social. El misericordioso parece capaz de muchas cosas; su zurrón está lleno de posibilidades de las que, en sus empresas con el mísero, sólo algunas de ellas podrán ser puestas en acto. El mísero, por el contrario, parece capaz de pocos trabajos; no le falta por principio el acto originario, esto es, el acto de existir, ni tampoco la energía, si bien éstos no consiguen introducirse en el mundo de los productos efectivos; su humanidad aparece como una realidad de segunda clase en comparación con la humanidad del poderoso misericordioso.

Sin embargo, hemos visto ya que el mismo misericordioso depende prácticamente de la llamada del mísero, y que sólo en este momento, escuchando la llamada y obedeciéndola, él actuará, ejercitará rectamente sus capacidades de acción en el mundo. Pongamos de relieve ahora que el mísero que pide una ayuda ejercita la única actividad expresiva de su ser que tiene a su alcance: "ayúdame». La llamada del mísero libera así un espacio para la actividad efectiva y recta del misericordioso. Si el mísero no llama, el misericordioso permanecerá inactivo, o se tambaleará su propia gloria; su acto permanecerá sin significación y su actividad será sólo vana. El misericordioso recibe del mísero la posibilidad de ser activo rectamente y de manifestar su acto de existir de un modo correcto, en una relación humana. Como hemos visto ya, un breve análisis crítico de la relación entre el misericordioso y del mísero pone de manifiesto que las características ingenuamente originarias del misericordioso que puede y del mísero que no puede, se ponen del revés. El mísero tiene el poder de dar la vida al misericordioso, esto es de darle espacio para que anime sus capacidades que, sin él, permanecerían sólo como meras posibilidades. 


\subsection{Petición de empatia}

Esta puesta del revés señala el carácter espiritual de la relación de misericordia. Ahora comienza una historia especificamente humana, sin la necesidad que caracteriza la relación fisica y moral del fuerte que se impone sobre el débil. Es la historia de un doble don, posible por las dos conversiones entrecruzadas y provocadas reciprocamente. En este encuentro surge la historia propiamente humana de las libertades en alianza. La realidad espiritual de la que se trata aquí es cumplida por las personas en relación en el evento de la misericordia pedida y dada. Los dones reales son reciprocos, pero diferentes: por una parte, el don real che es el requerimiento hic et nunc del mísero (sin esta petición, la acción del misericordioso permanece como mera posibilidad), y, por otra parte, el don hecho por el misericordioso que significa la apertura de espacios para el mísero (sin este don, el mísero permanece sin posibilidad).

Con todo, el mísero no podrá llamar al misericordioso si no ve en él de antemano algún don de posibilidades. La esperanza de que el misericordioso le ofrezca nuevos espacios de vida hace posible la llamada del mísero; de hecho, ésta proviene de la esperanza de salir de la soledad de su miseria; pide al misericordioso una participación en el bien que éste posee, que no es sólo un bien sensible o físico, sino también el de tener posibilidades de acción. La llamada del mísero constituye entonces una verdadera conversión, la cual no es sencilla, porque salir de sí significa siempre salir de ciertas representaciones cerradas del mundo y de las sociedades para abrirse a posibles actuaciones. La ausencia de posibilidades efectivas de acción impide imaginar nuevas posibilidades de vida, permite no arriesgar en aventuras incontrolables y cerrarse cada vez más en la miseria. Tampoco la conversión del misericordioso será fácil, antes que nada porque éste deberá abandonar la imagen de poderoso que tiene de sí, y después porque no podrá integrar al mísero en su cultura de poderoso capaz; su respuesta deberá medirse en virtud de las posibilidades limitadas de la persona real ayudada.

La persona misericordiosa, para poner en acto de modo adecuado su virtud de misericordia, esto es con respeto por el mísero, no puede no conocer, aunque sea de un modo larvado antes de la 
llamada del mísero, que sus propias posibilidades son limitadas, todavia más, que están sometidas a un destino de muerte. No hay verdadera misericordia sin compasión y capacidad de comunión con quien no está bien. Por ello, el misericordioso no puede tener sólo una representación de lo que constituiría el estado del mísero mediante su ayuda. Debe tener una idea de la miseria que procede de la propia experiencia y no sólo del estudio sociológico.

La verdadera misericordia supone la compasión ${ }^{11}$, la cual supone a su vez la simpatía, que supone además la empatía. La empatía perfecta, adaptada plenamente a las situaciones personales es, sin embargo, imposible. Los esfuerzos filosóficos llevados a cabo en esta dirección por parte de Husserl y más tarde por Edith Stein ${ }^{12}$, no han aportado conclusiones satisfactorias. No puedo jamás pretender conocer lo que el otro percibe dentro de sí mismo. De una persona a otra no existe jamás identidad perfecta en el autosentir. La empatía es imposible. No puedo saber nunca cómo este mísero vive su propia miseria; aunque puedo saber lo que significa no tener la posibilidad de ser ni de actuar.

El poderoso, obviamente, no es capaz de conocer la miseria vivida por las personas que encuentra; tendrá, como máximo, sólo una idea de la esencia de la miseria y de su sufrimiento. Para situarse en una relación adecuada o al mismo nivel con el mísero, el misericordioso debería, como mínimo, reconocer, en conciencia, que la propia vida le ha enseñado qué significa la miseria, esto es, la ausencia de posibilidades, y que dicha enseñanza es esencial para el desarrollo ético de su vida. La miseria conocida por el misericordioso, de este modo, no será ya para él una idea abstracta; el misericordioso comprenderá que

11 Para Santo Tomás de Aquino, "se dice misericordioso quien tiene el corazón lleno de compasión porque ante la miseria de los otros se aflige como si se tratase de la propia miseria" (Soma de teología, Ia p., q. 21, a. 3).Ver D. Galimberti, "Il metodo della misericordia" en Scuola cattolica 144 (2016) 46-48.

12 E. Stein, El problema de la empatía, disertación doctoral presentada en el 1916 (director: E. Husserl). Para Edith Stein, la problemática de la empatía es conectado con la de la persona. La persona es por esencia social. Sin embrago, aunque la empatía sea un acto originario en cuanto vivido en el presente de la persona, no es originario por su contenido, los demás, lo otro. 
se opone directamente a su autorrepresentación como poderoso. Podría quizá reconocer en este momento que también él es culpable, al considerar la propia resistencia a la humanización del prójimo, y por lo tanto de sí mismo.

El estudio y el análisis de las situaciones del mísero constituyen ocasiones que podrian hacer surgir la conciencia del estado de miseria del mismo misericordioso. Éste podrá entonces ejercitar concretamente, con justicia o equidad, su virtud de misericordioso, respetando la miseria real y compleja del mísero con quien se encuentra.

La puesta en acto de la misericordia, su "evento", pertenece entonces a una estructura real que es más que subjetiva, en el sentido de una subjetividad a priori autosuficiente. No es ni siquiera objetiva en el sentido que le otorgan a este término las ciencias empíricas modernas. Su realidad es original, relacional. El encuentro del misericordioso y del mísero supone una apertura mutua, a su propio mundo. Este encuentro es ético. Un encuentro ético no constituye un simple hecho, una síntesis de dos movimientos acordados perfectamente y en los que cada uno pierde su originalidad.

Es cierto que a primera vista el mísero se encuentra en una situación de la que quiere salir, y el misericordioso parece ocupar el polo opuesto, con el deber preciso de hacer todo lo posible para que el misero pueda efectivamente salir de su condición. Este tipo de relación no realiza sin embargo un verdadero encuentro entre personas; constituye sólo una relación de un poderoso con un impotente, el cual debería recibir del poderoso aquello de lo que carece. Hemos puesto ya de relieve la superficialidad de esta relación; es más, hemos considerado su injusticia estructural. Cuando el misericordioso corrige su buen corazón con el estudio de la situación del mísero, es necesario entonces convertirse, cuestionarse sobre aspectos de la situación que antes no habian sido conocidos con claridad, pero que ocurren ahora bajo la responsabilidad de su respuesta a la llamada. El misericordioso no conoce jamás de antemano todo sobre la persona mísera que encuentra, y no sabe de qué tendrá en verdad necesidad. 


\subsection{Poderoso e impotente}

Se abre aquí un espacio nuevo para el "poderoso", que puede tomar conciencia de la injusticia de las propias actividades, eventualmente también de la propia impotencia cuando se da cuenta de que es incapaz de injertarse en el mundo de las mediaciones adaptadas a las circunstancias del mísero. El misericordioso entonces lleva a cabo, bajo la presión de una ética de valores en general y de su práctica en lo concreto, un estudio de las mediaciones racionales, de las actividades posibles demandadas por aquello que descubrirá de las circunstancias, con frecuencia ocultas, del mísero. El espacio del estudio es demandado por una misericordia que pretende respetar a la persona mísera.

No se puede jamás pretender, sin embargo, conocer a las personas de un modo absolutamente completo. La razón humana no puede acceder a las responsabilidades que pertenecen al corazón de los demás. El mísero tiene derecho al secreto de su intimidad, como todo hombre; sin embargo, nadie está totalmente abierto ni siquiera a si mismo. Dicha apertura, experimentada con prudencia por parte del misericordioso que estudia las situaciones del mísero, ofrece a éste una posibilidad real de salvación, para que pueda moverse de su miseria, para que pueda creer que su miseria no es un destino fatal, sino una situación que puede ser afrontada en vistas a la liberación.

Desde esta perspectiva, el misericordioso tiene la iniciativa de proponer un bien que no sea sólo comunicado con poder, sino más radicalmente una apertura para un camino de libertad, que el mísero asumirá personalmente con responsabilidad. El poder ético del misericordioso inicia y concluye aquí, con respecto a sí mismo y no al mísero. No es lícito decir que el estado propio del misericordioso es el de poderoso rico que podría poner en acto su poder de cualquier modo, mientras que el estado propio del mísero es el de un impotente cerrado en su facticidad empírica, en la fatalidad. No podemos decir tampoco que el misericordioso es el único maestro de lo posible, y que el mísero estará siempre encerrado en la realidad inconmovible de su impotencia.

Podemos pasar ahora de las observaciones fenomenológicas a las afirmaciones metafísicas. Es más, podemos sostener que una 
nueva "ontologia", esto es, un nuevo lógos de las realidades últimas, deviene una tarea esencial para entender mejor el existir ético de los hombres y mujeres. Los términos "misericordioso" y "mísero" significan unas subjetividades abiertas, de modo diferente, una a la otra. La apertura del misericordioso no puede ser determinada sólo por las ocasiones de poner en acto su poder; la realización de su capacidad relacional pertenece esencialmente a su atención a las circunstancias reales del mísero. El término "mísero" es igualmente relacional, pero de un modo que parece, de entrada, impersonal; quien es mísero, carece, antes de nada, de relaciones concretas con los bienes disponibles en su sociedad y con las personas que saben cómo hacer para conseguirlos y utilizarlos. La capacidad relacional del mísero depende de su valentía en la demanda de ayuda.

Todo ello impone una idea no empirista de la realidad. La realidad no es sólo aquello que está presente en la inmediatez del hecho. Para el empirismo, las realidades serian simplemente cosas iguales unas a otras. Juzgar que toda realidad equivale a un hecho sensible no es sensato, puesto que este juicio no es un hecho, sino que expresa una decisión respecto al sentido de lo que es. La realidad es, de hecho, más un porvenir que un hecho consumado. La comunidad de personas es porvenir. Las realidades son valores precisamente porque están llegando. Las cosas, dadas y cerradas en su dar-se en el instante de su percepción, ciertamente son, pero sólo según una percepción finita. Pueden faltar de un instante a otro, aparecer entre dos momentos distintos de atención, desaparecer durante una distracción. La verdadera realidad, sin embargo, tiene más consistencia que esto; la constituye una finalidad inmanente que exige un esfuerzo común, una inteligencia organizadora, una perspectiva creadora, una decisión a favor del crecimiento de la entera comunidad humana y de cada persona en particular.

¿Es válida la idea de una realidad que es más real que lo real que perciben los sentidos, ya que creceria, porque estaría caracterizada por un movimiento finalizado por la comunidad humana, aunque ninguna determinación pueda ser fijada de antemano? ¿Es válida la idea de una realidad que sería en este mismo movimiento del que nunca vemos el fin y que, en principio, no culminará nunca definitivamente? Habitualmente, la cuestión de la realidad es considerada desde el punto de vista del conocimiento empírico 
que se apropia de las cosas hic et nunc. Pero, este conocimiento empírico non constituye el todo de la conciencia humana. Esta interpretación de la experiencia de la conciencia humana es demasiado superficial. El término "conciencia" es complejo. El prefijo "co" se puede entender según múltiples significados, por ejemplo el "co" de la adecuación siempre tendencial del intelecto a las cosas y el "co" de la lengua que los interlocutores comparten. La filosofia más rigurosa se sitúa propiamente más allá de estos niveles, donde las relaciones humanas hacen surgir continuamente nuevos eventos; considera que la conciencia es esencialmente abierta e intersubjetiva, jamás encerrada en el individuo, sino alimentada por un encuentro entre personas diferentes, como lo son el misericordioso y el mísero.

\section{DE LA FENOMENOLOGÍA AL EVANGELIO}

Hemos tocado ya en esta conferencia, el tema de la empatía, aunque sólo de pasada. Profundicemos ahora en ello. La dificultad del tema procede de la imposibilidad de conocer al otro, dado que me es imposible ocupar su lugar, identificarme con él, sentir lo que él siente. "Sólo quien ha vivido la vida y la muerte de un amigo sabe hasta qué punto no lo conocía", apuntaba Jean-Luc Marion ${ }^{13}$. El significado de "empatía" trae consigo los matices de "simpatía", o de "compasión", aunque lleva al extremo el alcance de éstos. Padecer "con" el otro no es lo mismo que padecer "adentrándome" en los afectos del otro. La simpatía permanece en el exterior, la empatía se dirige sin embargo hacia "adentro". La simpatía parece tan posible como la empatía imposible. ¿Cómo podría entonces padecer "con" el amigo si permanezco totalmente "afuera"? La simpatía no es una afección que me una a él; me pone sólo a su lado.

La dificultad de los filósofos cuando consideran la empatía ${ }^{14}$ procede en realidad de una cierta comprensión de la persona como

13 J.-L. MARion, "L'icône ou l'herméneutique sans fin" (primera versión en el 1998) en ID., De surcroît, 152.

14 Observo que el vocablo "empatía" no ha entrado en la Enciclopedia filosofica del Centro Studi Filosofici di Gallarate, Bompiani, Milano 2006. 
substancia, de acuerdo con el significado común del término. Una substancia sería toda realidad íntegra, unida en sí misma, compacta, cuyo "núcleo" (la expresión es de Edith Stein) sería incomunicable. De este núcleo nace, de hecho, la responsabilidad de la persona frente a los otros, a la sociedad, es decir su capacidad de responder de los propios actos. La identidad de la persona no es fisica, sino ética. Desde esta perspectiva, el término empatía podría significar, no tanto entrar en lo íntimo físico del otro, sino "exponer al otro la propia intimidad ética". "Empatia" no significa entonces una dinámica de identificación y de confusión de personas, sino, al contrario, el reconocimiento de una diferencia ética en la comunicación misma de las libertades.

Esta reflexión nos conduce al Evangelio. La misericordia es reactiva (lo había puesto de relieve Nietzsche, tal como hemos señalado antes), y esta relación implica concretamente al corazón, esto es nuestras vísceras. La miseria del otro puede atormentar, hacer mal a las partes más sensibles e interiores del organismo. En un artículo reciente, Jean-Pierre Sonnet, profesor de exégesis de la Gregoriana, mostraba que "el término splanchna, en el sentido de "vísceras" y por ello de "compasión", posee un uso relativamente escaso en la Biblia de los LXX. Este término, sin embargo, se ha convertido en los escritos judios que han precedido el Nuevo Testamento en el equivalente griego de las "vísceras" del Dios que tiene piedad y perdona. En los relatos de Mateo, Marcos y Lucas, el término tiene repetidamente a Jesús como sujeto" ${ }^{15}$.

Hagamos notar, no obstante, que no estamos aquí ante la presencia de una actitud de empatía, sino sólo de simpatía, de compasión. La "simpatía" de la que ciertamente participa el ser humano de Jesús. Sería dificil decir, en este punto, que sea una "empatía": Jesús no es la madre que acompaña el cuerpo muerto de su único hijo; puede sólo acompañar sus sentimientos, pero no adentrarse en ellos. La dinámica de la encarnación del Hijo, ¿es entendida por la fe cristiana como una verdadera empatía más que como una simpatía? ¿En qué sentido? La muerte en sí misma

15 J.-P. Sonnet, "Justice et miséricorde. Les attributs de Dieu dans la dynamique narrative du Pentateuque", en Nouvelle revue théologique 138 (2016) 21. 
injusta del hijo pequeño de la viuda manifiesta un mal que se impone a toda la humanidad y del que todos buscamos la liberación.

He aquí el punto esencial: la Encarnación del Hijo consagra la lucha más radical contra el mal en cuanto tal, contra el maligno. De hecho, el Hijo ha descendido al asumir nuestra humanidad, más profundamente que ninguno de nosotros. No ha conocido todos los dramas humanos, no ha conocido por ejemplo les enfermedades y tampoco la decadencia de la vejez, pero ha conocido al príncipe del mal, y lucha contra él.

La lucha del Hijo no deja atrás ningún efecto del maligno, sino que se dirige hasta la muerte más ignominiosa, en medio de algunos malhechores. Es ahí donde se cumple su lucha, y es en su resurrección donde se manifiesta, para los creyentes, la victoria final. Pablo tiene razón: si el Hijo no ha resucitado, vana es nuestra $\mathrm{fe}^{16}$. He aquí la empatía divina que abre caminos nuevos para la esperanza y para la acción de los hombres. El Señor ha descendido más bajo que nosotros, para elevarnos sobre el mal.

Concluyo. La misericordia en Cristo es empatía y perdón. El perdón da la perfección, hace vivir. Esta posibilidad se hace efectiva en el tiempo, abre un camino. Aunque el fin de esta temporalidad permanece inconcebible, sus etapas son bien claras. La persona sometida al mal sabe, contemplando el Evangelio, que puede aceptar un gesto de misericordia que desborda todo lo que podría pensar, que abre para él una nueva historia espiritual: la de una conversión efectuada con decisión personal: seguir a Cristo. Los medios de esta historia no podrán ser otros sino los medios de Cristo, la participación con él en aquello más horrible de nuestra humanidad humillada por el mal, no sólo para hacernos cargo de ella, sino sobre todo para identificarnos con el que padece, yresucitar con Cristo.

161 Cor 15,17 . 